\title{
A COMPARISON OF TWO TURBULENT DISPERSION PARAMETERISATIONS IN THE STABLE BOUNDARY LAYER USING LAGRANGIAN AND EULERIAN MODELS
}

\author{
Davidson Martins Moreira' \\ Jonas da Costa Carvalho \\ Antônio Gledson Goulart ${ }^{3}$ \\ Umberto Rizza ${ }^{4}$ \\ Cristina Mangia ${ }^{5}$ \\ Recebido em 14 de mai., 2002 / Aceito em 14 de nov., 2003 \\ Received Mai. 14, 2002 / Accepted Nov. 14, 2003
}

\section{ABSTRACT}

An Eulerian model and a Lagrangian particle model are used to study the dispersion of a contaminant released from a low height source in the Stable Boundary Layer (SBL). The Eulerian model is based on the solution of the advection-diffusion equation by the Laplace transform technique. The Lagrangian model is based on a generalized form of the Langevin equation. Turbulence inputs are parameterised according to two procedures capable of generating continuous values in all stability conditions and in all heights of Planetary Boundary Layer (PBL). Statistical indices were calculated to compare the predicted and observed values of ground-level concentration. According to the statistical analysis, predicted concentration values agree well with the observed ones.

Keywords: Turbulent parameterisation, Lagrangian model, Eulerian model

\section{RESUMO}

Um modelo Euleriano e um de partículas Lagrangeano são usados para estudar a dispersão de um contaminante liberado por uma fonte de altura baixa na Camada Limite Estável. 0 modelo Euleriano é baseado na solução da equação de difusão-advecçã̃o, utilizando-se a técnica da transformada de Laplace. 0 modelo Lagrangeano é baseado na forma generalizada da equação de Langevin. Os parâmetros turbulentos são determinados de acordo com duas parametrizações capazes de gerar valores contínuos em todas as condições de estabilidade e alturas na Camada Limite Planetária. Índices estatísticos foram calculados para comparar valores de concentração ao nível da superfície previstos e observados. De acordo com a análise estatística, as concentrações previstas concordam bem com as concentrações observadas.

Palavras-chave. Parametrização da Turbulência, modelo Lagrangeano, modelo Euleriano

\footnotetext{
'Universidade Luterana do Brasil - ULBRA. Engenharia Ambiental. Rua Miguel Tostes, 101 Prédio 11 - Sala 230 - CEP $92420-280$ - Bairro São Luís - Canoas - RS - Brasil. Tel.: +55 (51) 477-9285 - Fax: + 55 (51) 477-1313. E-mail: davidson@ulbra.tche.br

${ }^{2}$ Universidade Luterana do Brasil - ULBRA. Engenharia Ambiental. Rua Miguel Tostes, 101 Prédio 11 - Sala 230 - CEP $92420-280$ - Bairro São Luís - Canoas - RS - Brasil. Tel.: +55 (51) 477-9285 - Fax: +55 (51) 477-1313. E-mail: jonas@ulbra.tche.br

${ }^{3}$ URI - Departamento de Ciências Exatas e da Terra, Santo Ângelo. Rua Universidade das Missões, 464 - CEP 98.802-470. Bairro Universitário - Santo Ângelo - RS - Brasil. Tel.: +55 (55) 3313-7900 - Fax: +55 (55) 3313-7902. E-mail: agoulart@urisan.tche.br

${ }^{4}$ CNR ISAC - Sezione di Lecce, Str. Prov. Lecce-Monteroni km 1200, 73100, Lecce, Itália. Fax: +390832 298716. E-mail: u.rizza@isac.cnr.it

${ }^{5}$ CNR ISAC - Sezione di Lecce, Str. Prov. Lecce-Monteroni km 1200, 73100, Lecce, Itália. Fax: +390832 298716. E-mail: c.mangia@isac.cnr.it
} 


\section{INTRODUCTION}

In the last years, there has been a wide effort in understanding the Convective Boundary Layer turbulent structure and dispersion properties, while the development of Stable Boundary Layer (SBL) theories and parameterisations are still a challenge. This is due to several aspects like the coexistence of quite different phenomena in the SBL. The mathematical modelling of the SBL has encountered difficulties in several aspects, mainly because of either the low intensity of the turbulent energy and or the coexistence of quite different phenomena like intermittencies and gravity waves.

The most popular method for estimating dispersion in the stable boundary layer is based on the stability classification system proposed by Pasquill and then modified by Gifford. This PG system, as it is commonly known, relates the dispersion characteristics of the Planetary Boundary Layer (PBL) to routinely available meteorological observations. The PG system attempts to account for the effects of shear and buoyancy on turbulence generation through the wind speed at $10 \mathrm{~m}$ height, and the incoming solar radiation. The PG classification system is generally consistent with the turbulent structure of the PBL, however, the correspondence between the PG meteorological variables (wind speed, solar radiation, cloudiness) and the dispersion characteristics is qualitative and far from unique (VENKATRAM, 1988).

In this work, an Eulerian model and a Lagrangian particle model are used to simulate the dispersion of a passive pollutant emitted from a low source during the Prairie Grass dispersion experiment (BARAD, 1958). The Lagrangian model is a three-dimensional model based on generalized form of the Langevin equation and it can use the higher moments of the Eulerian Probability Density Function (PDF) of the wind velocity fluctuations. The Eulerian model is based on a discretization of the PBL in N sub-layers; in each sub-layers the advection-diffusion equation is solved by the Laplace transform technique, considering an average value for eddy diffusivity and the wind speed.

The turbulent parameters used as input in the Lagrangian (velocity fluctuations moments and Lagrangian decorrelation time scales) and in the Eulerian model (eddy diffusivity coefficient) are parameterised according to two procedures: Degrazia e outros (2000) and Hanna (1982). The parameterisations deal contemporary with neutral and convective conditions on one hand, and with neutral and slightly stable conditions, on the other hand. They are able to generate continuous values in all stability and in all heights in the PBL. In this study, measured crosswind-integrated concentrations obtained in the stable Prairie Grass field experiment are used to compare observed and predicted concentrations.
The main objective of this study is to evaluate a general turbulence parameterisation, which can be employed to describe the turbulent transport of contaminants emitted by a low source in a stable PBL.

\section{DESCRIPTION OF THE MODELS}

\section{Eulerian model}

Following Vilhena et al. (VILHENA et al., 1998; MOREIRA; DEGRAZIA; VILHENA, 1999, DEGRAZIA; MOREIRA; VILHENA, 2001; MANGIA et al., 2002), for a cartesian coordinate system in which the $x$ direction coincides with the average wind direction, the steady state advection-diffusion equation is written as (ARYA, 1995):

$U \frac{\partial \bar{c}}{\partial x}=\frac{\partial}{\partial x}\left(K_{x} \frac{\partial \bar{c}}{\partial x}\right)+\frac{\partial}{\partial y}\left(K_{y} \frac{\partial \bar{c}}{\partial y}\right)+\frac{\partial}{\partial z}\left(K_{z} \frac{\partial \bar{c}}{\partial z}\right)$

where $\bar{c}$ denote the average concentration, $U$ the mean wind speed and $K_{x^{\prime}} K_{y}$ and $K_{z}$ are the eddy diffusivities. The crosswind integration of the eq. (1) (neglecting the longitudinal diffusion) leads to:

$U \frac{\partial \overline{c^{y}}}{\partial x}=\frac{\partial}{\partial z}\left(K_{z} \frac{\partial \overline{c^{y}}}{\partial z}\right)$

subject to the boundary conditions of zero flux at the ground and at the top of the PBL, and a source with emission rate Q at height $H_{s}$ :

$K_{z} \frac{\partial \overline{c^{y}}}{\partial z}=0$ in $z=0, h$

$U \overline{c^{y}}(0, z)=Q \delta\left(z-H_{s}\right)$ in $x=0$,

where now $\overline{c^{y}}$ represents the average crosswind integrated concentration.

Bearing in mind the dependence of the $K_{z}$ coefficient and the wind speed profile Uon the variable $z$, the height $h$ of a SBL is discretized in Nsub-intervals in such a manner that inside each interval $K_{Z}(z)$ and $u(z)$ assume the average value:

$$
\begin{aligned}
& K_{n}=\frac{1}{z_{n}-z_{n-1}} \int_{z_{n-1}}^{z_{n}} K_{z}(z) d z \\
& U_{n}=\frac{1}{z_{n}-z_{n-1}} \int_{z_{n-1}}^{z_{n}} U(z) d z
\end{aligned}
$$


Therefore, the solution of problem (2) is reduced to the solution of N problems of the type:

$U_{n} \frac{\partial \overline{c_{n}^{y}}}{\partial x}=K_{n} \frac{\partial^{2} \overline{c_{n}^{y}}}{\partial z^{2}} \quad z_{n-1}<z<z_{n}$,

for $n=1: N$, where $\overline{c_{n}^{y}}$ denotes the concentration at the $n^{\text {th }}$ subinterval. To determine the $2 \mathrm{~N}$ integration constants the additional ( $2 \mathrm{~N}-2)$ conditions namely continuity of concentration and flux at the interface are considered:

$\overline{c_{n}^{y}}=\overline{c_{n+1}^{y}} n=1,2, \ldots(\mathrm{N}-1)$

$K_{n} \frac{\partial \overline{c_{n}^{y}}}{\partial z}=K_{n+1} \frac{\partial \overline{c_{n+1}^{y}}}{\partial z} n=1,2, \ldots(\mathrm{N}-1)$

Applying the Laplace transform in eq. (7) results:

$\frac{\partial^{2}}{\partial z^{2}} \overline{c_{n}^{y}}(s, z)-\frac{U_{n} s}{K_{n}} \overline{c_{n}^{y}}(s, z)=-\frac{U_{n}}{K_{n}} \overline{c_{n}^{y}}(0, z)(10)$

where $\overline{c_{n}^{y}}(s, z)=L_{p}\left\{c_{n}^{y}(x, z) ; x \rightarrow s\right\}$, which has the well-known solution:

$\overline{c_{n}^{y}}(s, z)=A_{n} e^{-R_{n} z}+B_{n} e^{R_{n} z}+\frac{Q}{2 R_{a}}\left(e^{-R_{n}\left(z-H_{s}\right)}-e^{R_{n}\left(z-H_{s}\right)}\right)$,

where, $R_{n}= \pm \sqrt{\frac{U_{n} s}{K_{n}}}$ and $R_{a}= \pm \sqrt{U_{n} K_{n} s}$

Finally, applying the interface and boundary conditions we come out with a linear system for the integration constants. Henceforth the concentration is obtained inverting numerically the transformed concentration $c^{y}$ by Gaussian quadrature scheme (HEYDARIAN; MULLINEAUX, 1989):

$$
\begin{aligned}
& \overline{c_{n}^{y}}(x, z)=\sum_{j=1}^{N i} A_{j} \frac{P_{j}}{x}\left(A_{n} e^{-\left(\sqrt{\frac{P_{j} U_{n}}{x K_{n}}}\right) z}+B_{n} e^{\left(\sqrt{\frac{P_{j} U_{n}}{x K_{n}}}\right) z}\right) \\
& \overline{c_{n}^{y}}(x, z)=\sum_{j=1}^{N i} A_{j} \frac{P_{j}}{x}\left[A_{n} e^{-\left(\sqrt{\frac{P_{j} U_{n}}{x K_{n}}}\right)^{z}}+B_{n} e^{\left(\sqrt{\frac{P_{j} U_{n}}{x K_{n}}}\right)^{z}}+\right. \\
& \left.\frac{1}{2} \frac{Q}{\sqrt{\frac{P_{j} K_{n} U_{n}}{x}}}\left(e^{-\left(z-H_{s}\right)\left(\sqrt{\left(\sqrt[P]{P_{j} W_{n}}\right.}\right)}-e^{\left(z-H_{s}\right)\left(\sqrt{\frac{P_{j} U_{n}}{x K_{n}}}\right)}\right)\right]
\end{aligned}
$$

The solution (12) is valid for layers that do not contain the contaminant source and $x>0$, once the quadrature scheme of Laplace inversion does not work for $x=0$. On the other hand, the solution (13) can be used to evaluate the concentration field in the layer that contains the continuous source. $A_{j}$ and $P_{j}$ are the weights and roots of the Gaussian quadrature scheme and are tabulated in the book by Stroud \& Secrest (1966). In the present, we used $N i=8$ because this value provides the desired accuracy with the smallest computational time.

\section{Lagrangian model}

LAMBDA is a Lagrangian stochastic particle model based on a three-dimensional form of the Langevin equation for the random velocity (THOMSON, 1987). The velocity and the displacement of each particle are given by the following equations (RODEAN, 1996):

$d u_{i}=a_{i}(\mathrm{x}, \mathrm{u}, t) d t+b_{i j}(\mathrm{x}, \mathrm{u}, t) d W_{j}(t)$,

and

$$
d \boldsymbol{x}=(\boldsymbol{U}+\boldsymbol{u}) d t,
$$

where $i, j=1,2,3, \boldsymbol{x}$ is the displacement vector, $\boldsymbol{U}$ is the mean wind velocity vector, $\boldsymbol{u}$ is the Lagrangian velocity vector [velocity of a fluid particle associated to the turbulent velocity fluctuation (TAYLOR, 1921)], $a_{i}(\boldsymbol{x}, \boldsymbol{u}, t) d t$ is a deterministic term and $b_{i j}(\boldsymbol{x}, \boldsymbol{u}, t) d W_{j}(t)$ is a stochastic term and the quantity $d W_{j}(t)$ is the incremental Wiener process. The Wiener process is a continuous but not differentiable time integral of the "white noise", $\xi(t) . \xi(t)$ is a hypothetical stationary, Gaussian, stochastic process with constant spectral density on the real frequency axis.

Thomson considered the Fokker-Planck equation (RODEAN, 1996) as Eulerian complement of the Langevin equation to obtain the deterministic coefficient $a_{i}(\boldsymbol{x}, \boldsymbol{u}, t)$. The stationary Fokker-Planck equation is given as:

$$
\frac{\partial}{\partial x_{i}}\left(u_{i} P_{E}\right)=-\frac{\partial}{\partial u_{i}}\left(a_{i} P_{E}\right)+\frac{\partial^{2}}{\partial u_{i} \partial u_{j}}\left(\frac{1}{2} b_{i j} b_{j k} P_{E}\right),
$$

where $P_{E}(\boldsymbol{x}, \boldsymbol{u}, t)$ is the non-conditional PDF of the Eulerian velocity fluctuations and the other symbols have the same definitions as in eqs. $(14 \mathrm{a}, \mathrm{b})$. The deterministic coefficient $a_{i}(\boldsymbol{x}, \boldsymbol{u}, t)$ is obtained from:

$$
a_{i} P_{E}=\frac{\partial}{\partial x_{i}}\left(\frac{1}{2} b_{i j} b_{j k} P_{E}\right)+\phi_{i}(\mathrm{x}, \mathrm{u}, t)
$$


$\frac{\partial \phi_{i}}{\partial u_{i}}=-\frac{\partial P_{E}}{\partial t}-\frac{\partial}{\partial x_{i}}\left(u_{i} P_{E}\right)$

subject to the condition:

$\phi_{i} \rightarrow 0$ when $\boldsymbol{u} \rightarrow \infty$

While in the two horizontal directions the $P_{E}$ is considered to be Gaussian, in the vertical direction the PDF is assumed to be nonGaussian (to deal with non-uniform turbulent conditions and/or convection). In this latter case, two different approaches can be adopted in order to calculate the Fokker-Planck equation: a bi-Gaussian equation, truncated to the third order, and a Gram-Charlier equation, truncated to the third or to the fourth order (ANFOSSI et al., 1997; FERRERO; ANFOSSI, 1998). The bi-Gaussian PDF is given by the linear combination of two Gaussians (BAERENTSEN; BERKOWICZ, 1984) and the GramCharlier PDF is a particular type of expansion that uses orthonormal functions in the form of Hermit polynomials.

The coefficient $b_{i j}(\boldsymbol{x}, \boldsymbol{u}, t)$ is obtained from the following Lagrangian structure function (the ensemble average of the square of the change in Lagrangian velocity in the time interval $\Delta t$ ):

$$
D(\Delta t)=\left\langle\left[u_{i}(t+\Delta t)-u_{i}(t)\right]^{2}\right\rangle=\left\langle\left(\Delta u_{i}\right)^{2}\right\rangle
$$

For the inertial subrange $\left(\tau_{K}<<\Delta t<<\tau_{L}\right)$, where $\tau_{K}$ is the Kolmogorov time scale and $\tau_{L}$ is the Lagrangian decorrelation time scale, the structure function is given by:

$$
D(\Delta t)=C_{0} \varepsilon(\mathrm{x}, t) \Delta t,
$$

where $C_{0}$ is the Kolmogorov constant (between 2 and 7 Rodean, 1994; Degrazia; Anfossi, 1998) and $\varepsilon(\boldsymbol{x}, t)$ is the ensembleaverage rate of dissipation of turbulent kinetic energy. Using the square of eq. (14 a) and applying the conditions for the Wiener process, the change in Lagrangian velocity is:

$$
\left\langle\left(\Delta u_{i}\right)^{2}\right\rangle=b_{i j}^{2} \Delta t \text {. }
$$

Then, from eqs. (19) and (20), it is possible to show that $b_{i j}(\boldsymbol{x}, \boldsymbol{u}, t)$ is related to $C_{0}$ in the following way:

$b_{i j}=\delta_{i j} \sqrt{C_{0} \varepsilon}$, where $\delta_{i j}$ is the Kronecker delta. In particular this means that the Lagrangian structure function constant $C_{0}$ is an important quantity in stochastic Lagrangian models of turbulent diffusion. On the other hand, the product $\sqrt{C_{0} \varepsilon}$ can also be written as a function of the variance of the velocity fluctuantions $\sigma_{i}^{2}$ and the Lagrangian decorrelation time scales $\tau_{L_{i}}$ (HINZE, 1975; TENNEKES, 1982):

$C_{0} \varepsilon=2 \frac{\sigma_{i}^{2}}{\tau_{L_{i}}}$.

Therefore, $\sqrt{C_{0} \varepsilon}$ can be substituted by $\sqrt{2 \sigma_{i}^{2} / \tau_{L_{i}}}$, demonstrating that $\sigma_{i}^{2}$ and $\tau_{L_{i}}$ are important inputs in the stochastic Lagrangian models of turbulent diffusion.

The concentration field is determined by counting the particles in a cell or imaginary volume in the position $x, y, z$ :

$C(x, y, z, t)=\frac{m_{p} N_{v}}{V_{C}}$,

where $m_{p}$ is the particle mass, $N_{v}$ is the particle number inside the cell and $V_{C}$ is the cell volume (irregular over complex terrain). The particle mass is determined by:

$m_{p}=\frac{Q(t) N_{\Delta t}}{N_{p}}$,

where $Q$ is the emission rate, $N_{\Delta t}$ is the number of time steps and $N_{p}$ is the number of emitted particles per time step.

\section{TURBULENCE PARAMETERISATION}

In the present application the turbulence parameterisation schemes suggested by Degrazia et al. (2000) parameterisation and by Hanna (1982) parameterisation were considered, as described below:

Accounting for the current knowledge of the PBL structure and characteristics, the authors derived parameterisations for wind velocity variances $\left(\sigma_{i}^{2}\right)$, decorrelation time scales $\left(\tau_{L i}\right)$ and diffusion coefficients $\left(K_{i}\right)$. The classical statistical diffusion theory, the observed spectral properties where a linear combination of the two turbulent forcing mechanisms (shear + buoyancy) (FRISCH, 1995) and observed characteristics of energy containing eddies were used to estimate these parameters. These parameterisations give continuous values for the PBL at all elevations $\left(z_{0} \leq z \leq z_{i}, h\right)$ and all stability conditions from unstable to stable $(-\infty<L<\infty)$, where $z_{i}$ is the convective PBL height and $h$ is the neutral or stable PBL height, $z_{0}$ is the aerodynamic roughness length and $L$ is the Monin-Obukhov length. The general expressions for $\sigma_{i}^{2}, \tau_{L i}$ and $K_{i}$ are the following: 
$\underset{(25)}{\sigma_{i}^{2}}=\frac{1.06 c_{i}\left(\psi_{\varepsilon}^{c} \frac{z}{z_{i}}\right)^{2 / 3} \mathrm{~W}_{*}^{2}}{\left[\left(f_{m}^{*}\right)_{i}^{c}\right]^{2 / 3}}+\frac{2.32 c_{i}\left(\phi_{\varepsilon}^{n+s}\right)^{2 / 3} u_{*}^{2}}{\left[\left(f_{m}^{*}\right)_{i}^{n+s}\right]^{2 / 3}}$,

$\tau_{L_{i}}=\frac{z}{\sqrt{c_{i}}}\left\{\frac{0.14\left(\frac{-\bar{L} z_{i}}{z_{i}-L}\right)^{1 / 2}}{\left[\left(f_{m}^{*}\right)_{i}^{c}\right]^{2 / 3} w_{*}\left(\psi_{\varepsilon}^{c} \frac{z}{z_{i}}\right)^{1 / 3}}+\frac{0.059}{\left[\left(f_{m}^{*}\right)_{i}^{n+s}\right]^{2 / 3}\left(\phi_{\varepsilon}^{n+s}\right)^{1 / 3} u_{*}}\right\}$

and

$$
K_{i}=0.14 \sqrt{c_{i}} z\left\{\frac{\left(\psi_{\varepsilon}^{c} \frac{z}{z_{i}}\right)^{1 / 3}\left(\frac{-\bar{L} z_{i}}{z_{i}-L}\right)^{1 / 2} w_{*}}{\left[\left(f_{m}^{*}\right)_{i}^{c}\right]^{4 / 3}}+\frac{\left(\phi_{\varepsilon}^{n+s}\right)^{1 / 3} u_{*}}{\left[\left(f_{m}^{*}\right)_{i}^{n+s}\right]^{4 / 3}}\right\}
$$

where $w_{*}$ is the convective velocity scale, $u_{*}$ is the local friction velocity, $\psi_{\varepsilon}^{c}=\varepsilon z_{i} / w_{*}^{3}$ and $\phi_{\varepsilon}^{n+s}=\varepsilon \kappa z / u_{*}^{3}$ are the nondimensional molecular dissipation rate functions associated to buoyancy and mechanical productions, respectively, $\left(f_{m}^{*}\right)_{i}^{c}$ is the reduced frequency of the convective spectral peak, $\left(f_{m}^{*}\right)_{i}^{n+s}$ is the reduced frequency of the neutral or stable spectral peak, $-\bar{L} / z_{i}$ is an average stability parameter for the $\mathrm{CBL}, \kappa$ is the Von Karman constant and $c_{i}=\alpha_{i}(0.5 \pm 0.05)(2 \pi k)^{-2 / 3}$ with $\alpha_{i}=1,4 / 3,4 /$ 3 for $u$, vand $w$ components, respectively.

\section{HANNA (1982) PARAMETERISATION}

The parameterisation proposed by Hanna (1982) is widely used in pollutant dispersion models. This parameterisation describes the turbulence field from the surface layer and boundary layer parameters $z_{0}, L, u_{*}, w_{*}, h$ and $z_{i}$. Hanna suggested, from Minnesota PBL observations, different expressions for the variances and for the Lagrangian time scales distinguishing the different kind of atmospheric stratification conditions, the unstable, stable and neutral cases. For the stable case, the expressions for $\sigma_{i}^{2}$ and $\tau_{L_{i}}$ are the following:

$$
\begin{aligned}
& \sigma_{u}=2 u_{*}\left(1-\frac{z}{h}\right) \\
& \sigma_{w}=\sigma_{v}=1.3 u_{*}\left(1-\frac{z}{h}\right) \\
& \tau_{L_{u}}=0.15 \frac{h}{\sigma_{u}}\left(\frac{z}{h}\right)^{0.5}
\end{aligned}
$$

$$
\begin{aligned}
\tau_{L_{v}} & =0.07 \frac{h}{\sigma_{v}}\left(\frac{z}{h}\right)^{0.5} \\
\tau_{L_{w}} & =0.10 \frac{h}{\sigma_{w}}\left(\frac{z}{h}\right)^{0.8}
\end{aligned}
$$

where $K_{i}$ is given by the relation:

$$
K_{i}=\tau_{L_{i}} \sigma_{i}^{2}
$$

\section{TEST OF THE EULERIAN AND LAGRANGIAN MODELS}

The models' performances have been evaluated against experimental concentrations using tracer $\mathrm{SO}_{2}$ from Prairie Grass dispersion experiments by Barad (1958) described by Barad (1958). The tracer was released without buoyancy at a height of $\sim 0.5 \mathrm{~m}$, and colleted at a height of $1.5 \mathrm{~m}$ at three downwind distances $(50,200$ and $800 \mathrm{~m})$. The Prairie Grass site was quite flat and much smooth with a roughness length of $0.6 \mathrm{~cm}$. We present here the results for 27 stable runs, for which the condition $h / L>0$ is satisfied. In these runs the dispersion is generated by mechanical processes (competition between wind-shear and positive buoyancy) and as a consequence only the second terms of the right-hand side of the eqs (25), (26) and (27) were utilized to parameterise the turbulent transport in the Eulerian and Lagrangian dispersion models. The micrometeorological parameters recorded during the dispersion experiments are summarized in Table 1, based on the paper of van Ulden (1978). To calculate $h$, the relation $h=0.4\left(u_{*} L / 10^{-4}\right)^{1 / 2}$ was used (ZILITINKEVICH, 1972). An exponential wind vertical profile was calculated from the wind speed measured during the experiment.

In the Lagrangian particle model, the horizontal domain was determined according to sample distances and the vertical domain was set equal to the observed mixing height. The time step was maintained constant and it was obtained according to the value of the Lagrangian decorrelation time scale ( $\Delta t=\tau_{L_{i}} / c$ ), where $\tau_{L_{i}}$ must be the smaller value between $\tau_{L_{u}}, \tau_{L_{v}}, \tau_{L_{w}}$ and $c$ is an empirical coefficient set equal to 10 . Fifty particles were released at each time step during 1500 - 2000 time steps. The PDF Gram-Charlier truncated to the fourth order was chosen.

The performances of the models are shown in Table 2 and in Figures 1 and 2. Table 2 shows the result of the statistical analysis considering the following statistical indices (HANNA, 1989): 
Tabela 1 - Parâmetros meteorológicos medidos durante 0 experimento Prairie Grass.

Table 1 - Meteorological parameters measured during the Prairie Grass experiment.

\begin{tabular}{ccccc}
\hline Run & $u_{*}\left(\mathrm{~ms}^{-1}\right)$ & $L(\mathrm{~m})$ & $h(\mathrm{~m})$ & $U\left(\mathrm{~ms}^{-1}\right)$ \\
\hline 13 & 0.09 & 3.4 & 23 & 3.9 \\
14 & 0.05 & 1.6 & 12 & 3.7 \\
17 & 0.21 & 48 & 131 & 3.8 \\
18 & 0.2 & 25 & 92 & 4 \\
21 & 0.38 & 172 & 333 & 6.4 \\
22 & 0.46 & 204 & 400 & 7.7 \\
23 & 0.39 & 193 & 358 & 6.5 \\
24 & 0.38 & 248 & 400 & 6.3 \\
28 & 0.16 & 24 & 81 & 3.2 \\
29 & 0.23 & 36 & 119 & 4.3 \\
32 & 0.13 & 8.3 & 43 & 3.6 \\
35 & 0.24 & 53 & 147 & 4.3 \\
36 & 0.1 & 7.8 & 36 & 2.8 \\
37 & 0.29 & 95 & 216 & 5 \\
38 & 0.28 & 99 & 217 & 4.8 \\
39 & 0.14 & 9.8 & 48 & 3.6 \\
40 & 0.11 & 8 & 39 & 3.1 \\
41 & 0.23 & 35 & 117 & 4.4 \\
42 & 0.37 & 120 & 275 & 6.3 \\
46 & 0.34 & 114 & 257 & 5.8 \\
53 & 0.17 & 10 & 54 & 4.3 \\
54 & 0.24 & 40 & 128 & 4.5 \\
55 & 0.37 & 124 & 279 & 6.3 \\
56 & 0.29 & 76 & 194 & 5.1 \\
58 & 0.11 & 6.4 & 35 & 3.4 \\
59 & 0.14 & 11 & 51 & 3.4 \\
60 & 0.28 & 58 & 166 & 5 \\
\hline & & & &
\end{tabular}

NMSE $=\overline{\left(C_{o}-C_{p}\right)^{2}} / \overline{C_{o} C_{p}}$ (Normalized Mean Square Error)

$$
\begin{aligned}
& F B=\left(\overline{C_{o}}-\overline{C_{p}}\right) /\left(0.5\left(\overline{C_{o}}+\overline{C_{p}}\right)\right) \quad \text { (Fractional } \\
& \text { Bias) } \\
& F S=2\left(\sigma_{o}-\sigma_{p}\right) /\left(\sigma_{o}+\sigma_{p}\right) \quad \text { (Fractional }
\end{aligned}
$$

$$
R=\left(\overline{\left.C_{o}-\overline{C_{o}}\right)\left(C_{p}-\overline{C_{p}}\right) / \sigma_{o} \sigma_{p}} \begin{array}{r}
\text { (Correlation } \\
\text { Coefficient })
\end{array}\right.
$$

$F A 2=0.5 \leq C_{o} / C_{p} \leq 2$

(Factor 2)

where $C$ is the analysed quantity (concentration) and the subscripts " $\theta$ " and " $p$ " represent the observed and the predicted values, respectively. The overbars in the statistical indices indicate averages. The statistical index $F B$ indicates weather the predicted quantities underestimates or overestimates the observed ones. The statistical index NMSErepresents the quadratic error of the predicted quantities in relation to the observed ones. Best results are indicated by values nearest zero in NMSE, FB and $F S$, and nearest 1 in $R$ and $F A 2$. Figures 1 and 2 show the observed and predicted scatter diagram of crosswind concentrations for the Lagrangian and Eulerian models using Degrazia e outros (2000) and Hanna (1982) parameterisations, respectively.

Analysing the statistical indices in Table 2 it is possible to notice that the models simulate satisfactorily the observed concentrations, with NMSE, FBand $F S$ values relatively near to zero and $R$ and $F A 2$ relatively near to 1 . A more detailed inspection of the Table 2 permits to observe that the Eulerian model with Hanna (1982) parameterisation presents best values of NMSE while the Lagrangian model with Hanna (1982) parameterisation presents best values of $F B$. For the other statistical indices, there are not considerable differences between the results. All the values for the indices are within ranges that are characteristics of those found for other state-of-the-art models applied to other field datasets, thus showing that the models and the turbulence parameterisations are quite effective.

\section{CONCLUSIONS}

In this work an Eulerian model and a Lagrangian stochastic particle model were used to simulate the transport and diffusion of a passive pollutant released during the stable Prairie Grass dispersion experiments. The particle model is based on three-dimensional form of the Langevin equation for the random velocity and it can simulate the dispersion of pollutants under complex meteorological conditions from sources of different geometries. The Eulerian model is based on a discretization of the Planetary Boundary Layer in Nsub-layers; in each sub-layer the advection-diffusion equation is solved by the Laplace transform technique, considering an average value for eddy diffusivity and the wind speed. The parameterisations proposed here and used in 
Tabela 2 - Índices estatísticos da performance do modelo para 0 experimento Prairie Grass.

Table 2 - Statistical indices of the model performance for the Prairie Grass experiment.

\begin{tabular}{cccccc}
\hline Model & $N M S E$ & $F A 2$ & $R$ & $F B$ & $F S$ \\
\hline Eulerian (Degrazia et al., 2000) & 0.49 & 0.82 & 0.77 & -0.224 & -0.258 \\
Lagrangian (Degrazia et al. 2000) & 0.66 & 0.94 & 0.77 & -0.152 & -0.390 \\
Eulerian (Hanna, 1982) & 0.47 & 0.93 & 0.79 & 0.275 & 0.267 \\
Lagrangian (Hanna, 1982) & 0.58 & 0.91 & 0.75 & -0.035 & -0.263 \\
\hline
\end{tabular}

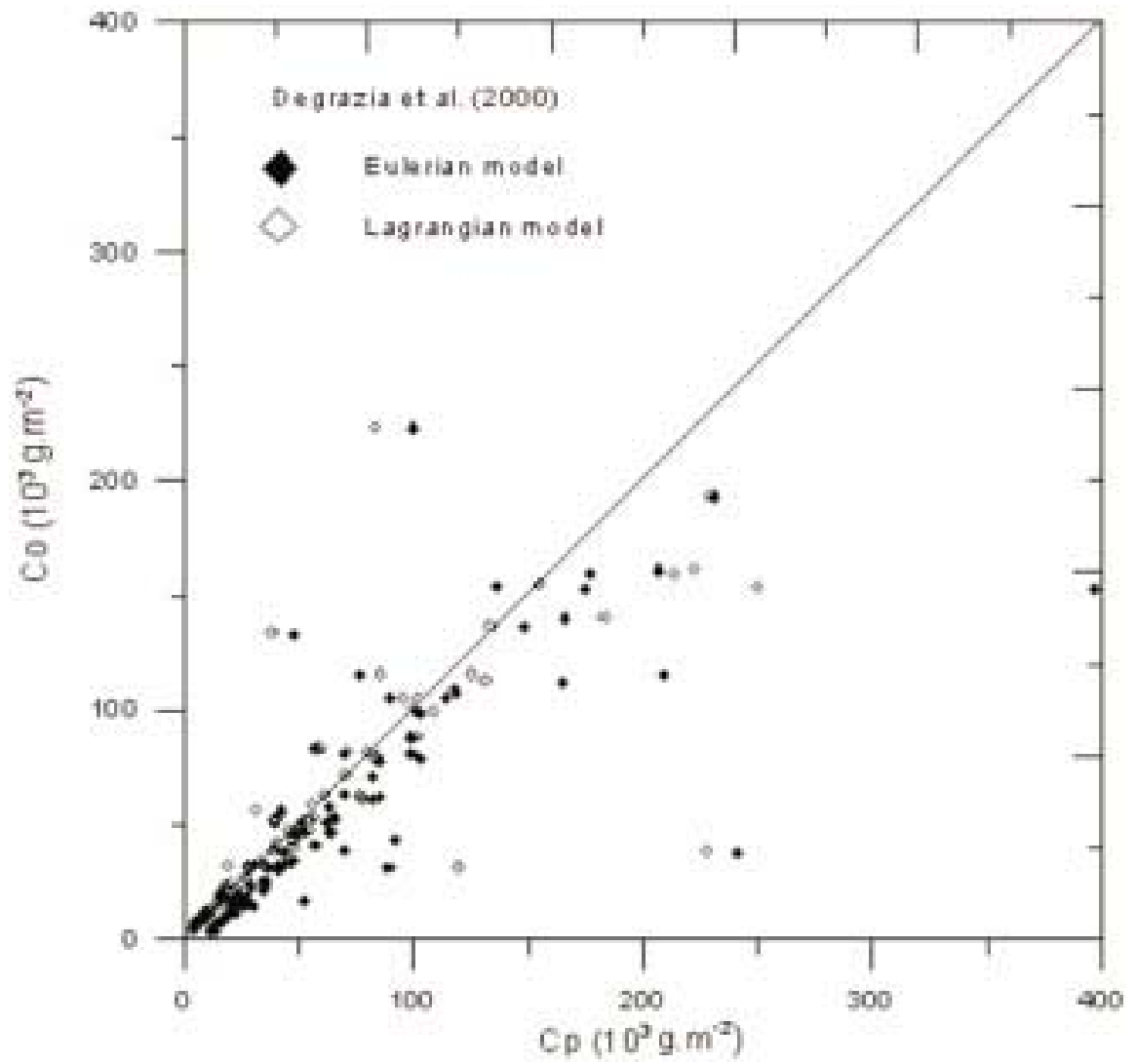

Figura 1 - Diagrama de espalhamento entre concentrações observada e prevista ao nível da superfície integrada perpendicularmente a direção do vento $\left[\left(\overline{c^{y}} / Q\right) \cdot 10^{3}\right]$ para os modelos Euleriano e Lagrangeano utilizando a parametrização de Degrazia et al. (2000).

Figure 1 - Scatter diagram between observed (Co) and predicted (Cp) ground-level cross-wind integrated concentrations $\left[\left(c^{y} / Q\right) .10^{3}\right]$ for the Lagrangian and Eulerian models using Degrazia et al. (2000) parameterisation. 


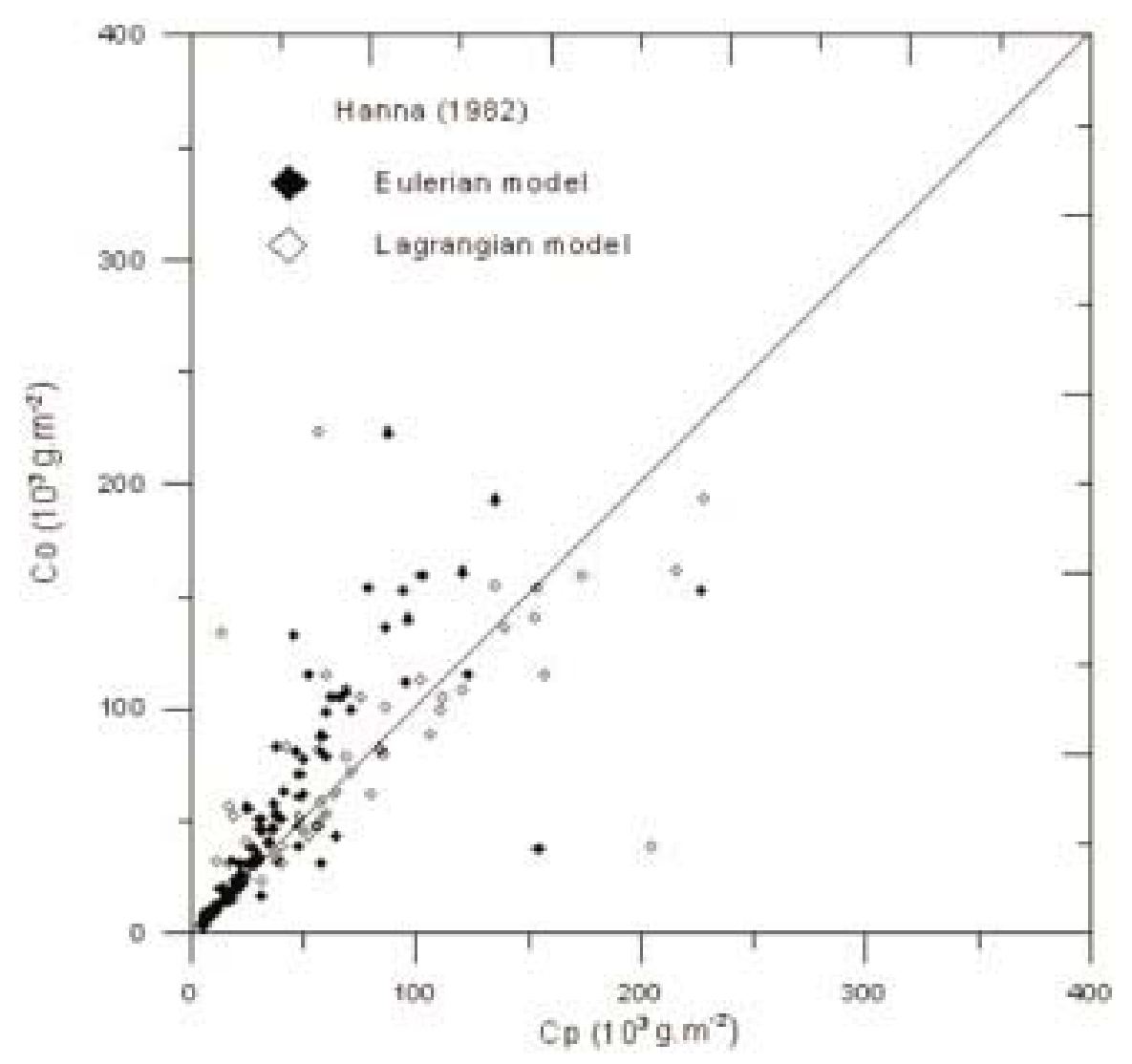

Figura 2 - Diagrama de espalhamento entre concentrações observada e prevista ao nível da superfície integrada perpendicularmente a direção do vento $\left[\left(\overline{c^{y}} / Q\right) \cdot 10^{3}\right]$ para os modelos Euleriano e Lagrangeano utilizando a parametrização de Hanna (1982).

Figure 2 - Scatter diagram between observed (Co) and predicted (Cp) ground-level cross-wind integrated concentrations $\left[\left(\overline{c^{y}} / Q\right) \cdot 10^{8}\right]$ for the Lagrangian and Eulerian models using Hanna (1982) parameterisation.

the Lagrangian (turbulent velocity moments and Lagrangian decorrelation time scales) and Eulerian (eddy diffusivity coefficient) models are provided by two different methods. The first method, Degrazia e outros (2000), based on Taylor's statistical diffusion theory and the observed spectral properties, supposes a linear combination between shear and buoyancy turbulence. This parameterisation for the stable Prairie Grass runs take into account the competition between wind-shear generated turbulence and stabilising effects of stratification $(L>0)$. The second method, Hanna (1982), is based on observed spectral properties from Minnesota PBL observations. Some statistical indices were calculated to compare the simulated and observed values of ground-level concentration. Analysis of the results and the application of statistical indices show that the models, with the proposed turbulence parameterisations, produce a good fit of the measured ground-level cross-wind concentration. The major advance that we want to highlight from in this study relies in the particularities of the turbulence parameterisations, which allow an 
accurate description of the turbulent transport for a low source in terms of the characteristic velocity and length scales of thermal and mechanical energy containing eddies. In conclusion, it can be said that there is a general agreement between observed and predicted ground-level concentrations for both models (Lagrangian and Eulerian). The results obtained are encouraging, so that the parameterisations here presented may be used in regulatory air pollution modelling.

\section{Acknowledgments}

The authors are gratefully indebted to CNPq (Conselho Nacional de Desenvolvimento Científico e Tecnológico) and FAPERGS (Fundação de Amparo à Pesquisa do Estado do Rio Grande do Sul) for the partial financial support of this work and CESUP (Centro Estadual de Supercomputação) for the computational support.

\section{REFERENCES}

ANFOSSI D. et al. Comparison among empirical probability density functions of the vertical velocity in the surface layer based on higher order correlations. Boundary-Layer Meteorolical, [S.I.], v. 82, p. 193218, 1996.

et al. A simplified version of the correct boundary conditions for skewed turbulence in lagrangian particle models. Atmospheric Environment, [S.I.], v. 31, p. 301-308, 1997.

ARYA P. S. Modelling and parameterisation of near-source diffusion in weak winds. Journal of Applied Meteorology, [S.I.], v. 34, p. 1112 1122, 1995.

BAERENTSEN, J. H.; BERKOWICZ, R. Monte Carlo simulation of plume dispersion in the convective boundary layer. Atmospheric Environment, [S.I.], v. 8, p. 701-712, 1984.

BARAD, M. L. (Ed.). Project prairie grass: a field program in diffusion. Geophysical Research Paper, [S.I.], v. 2, n. 59, 1958.

DEGRAZIA G.; ANFOSSI D. Estimation of the Kolmogorov constant $C_{0}$ from classical statistical diffusion theory. Atmospheric Environment, [S.I.], v. 32, p. 3611-3614, 1998.

et al. Turbulence parameterisation for PBL dispersion models in all stability conditions. Atmospheric Environment, [S.I.], v. 34, p. 3575-3583, 2000.

; MOREIRA, D. M.; VILHENA, M. T. Derivation of an eddy diffusivity depending on source distance for vertically inhomogeneous turbulence in a convective boundary layer. Journal of Applied Meteorology, v. 40, [S.I.], p. 257-264, 2001.
FERRERO E.; ANFOSSI D. Comparison of PDFs, closures schemes and turbulence parameterisations in Lagrangian Stochastic Models. Int. J. Environ. and Pollution, [S.I.], v. 9: p. 384-410, 1998.

FRISCH U. Turbulence. New York: Cambridge University Press, 1995. HANNA S. R. Applications in air pollution modeling. In: NIEUWSTADT F. T. M.; VAN DOP H. (Ed.). Atmospheric turbulence and air pollution modelling. Dordrecht: Reidel, 1982. p. 275-310.

Confidence limit for air quality models as estimated by bootstrap and jacknife resampling methods. Atmospheric Environment, [S.I.], v. 23, p. 1385-1395,1989.

HEYDARIAN M.; MULLINEAUX N. Solution of parabolic partial differential equations. Appl. Math. Modelling, [S.I.], v. 5, p. 448-449, 1989.

HINZE, J.O. Turbulence. New York: Mc Graw Hill, 1975.

HOLISLAG, A. A.; MOENG, C. H. Eddy diffusivity and counter-gradient transport in the convective boundary layer, Journal of Atmospheric Science, [S.I.], v. 48, p. 1690-1698, 1981.

KAIMAL J. C. et al. Turbulence structure in the convective boudary layer. Journal Atmospheric Sciences, [S.I.], v. 33, p. 2152-2169, 1976.

; FINNIGAN J. J. Atmospheric boundary fayer flows. Oxford:

Oxford University Press, 1994.

MANGIA, C. et al. Evaluation of a new eddy diffusivity parameterisation from turbulent Eulerian spectra in different stability conditions. Atmospheric Environment, [S.I.], v. 36, p. 67-76, 2002.

MOREIRA D. M.; DEGRAZIA G. A.; VILHENA M. T. Dispersion from low sources in a convective boundary layer: an analytical model. // Nuovo Cimento, [S.I.] v. 22C, n. .5, p. 685-691, 1999.

NIEUWSTADT F. T. M. The turbulent structure of the stable nocturnal boundary Layer. Journal of the Atmospheric Sciences, [S.I.], v. 41, p. 2202-2216, 1984.

OLESEN H. R.; LARSEN S. E.; HfJSTRUP J. Modelling velocity spectra in the lower part of the planetary boundary layer. Boundary-Layer Meteorolical, [S.I.], v. 29, p. 285-312, 1984.

PAULSEN C. A. The mathematical representation of wind and temperature profiles in a unstable atmospheric surface layer. Journal Applied Meterology, [S.I.], v. 9, p. 857-861, 1975.

RODEAN, H. C. Notes on the Langevin model for turbulent diffusion of "marked" particles. UCRL-ID-115869. Livermore: Lawrence Livermore National Laboratory, 1994.

Stochastic lagrangian models of turbulent diffusion. American Meteorological Society, Boston, v. 26, 1996.

STROUD, A. H.; SECREST D. Gaussian quadrature formulas. Englewood Cliffs: Prentice-Hall, 1966.

TAYLOR, G. I. Diffusion by continuous movements. Proc.London Math. Soc., [S.I.], v. 20, p. 196-212, 1921. 
TENNEKES, H. Similarity relation, scaling laws and spectral dynamics. In: NIEUWSTADT F. T. M.; VAN DOP, H. (Ed.). Atmospheric turbulence and air pollution modelling. Dordrecht: Reidel, 1982. p. 37- 68. THOMSON, D. J. Criteria for the selection of stochastic models of particle trajectories in turbulent flows. Journal Fluid Mechanics, [S.I.], v. 180, p. 529-556, 1987.

VAN ULDEN A. P. Simple estimates for vertical dispersion from sources near the ground. Atmospheric Environment, [S.I.], v. 12, p. 2125-2129, 1978.
VILHENA M. T. et al. An analytical air pollution model: development and evalution. Meteorology and Atmospheric Physics, [S.I.], v. 71, n. 3, p. 315-320, 1998.

VENKATRAM, A. Dispersion in the stable boundary layer, lectures on air pollution modelling. American Meteorologica/ Societt, Boston, p. 229$265,1988$.

ZILITINKEVITH S. S. On the determination of the height of the Ekman boundary layer. Boundary Layer Meteorological, [S.I.], v. 3, p. 141145, 1972. 